\title{
Let them speak for themselves: Improving adolescent self-report rate on pre-visit screening
}

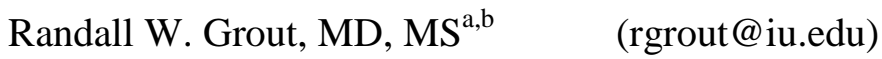

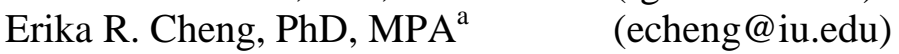 \\ Matthew C. Aalsma, $\mathrm{PhD}^{\mathrm{c}} \quad$ (maalsma@iu.edu) \\ Stephen M. Downs, MD, MS $\quad$ (stmdowns@iu.edu)
}

\section{Affiliations \\ ${ }^{a}$ Children's Health Services Research, Department of Pediatrics, School of Medicine, Indiana University, $410 \mathrm{~W} 10^{\text {th }} \mathrm{St}$, HS 2000, Indianapolis, IN, 46202 \\ ${ }^{\mathrm{b}}$ Regenstrief Institute, Inc, $1101 \mathrm{~W} 10^{\text {th }} \mathrm{St}$, Indianapolis, IN, 46202 \\ ${ }^{\mathrm{c}}$ Adolescent Medicine, Adolescent Behavioral Health Research Program, Department of Pediatrics, School of Medicine, Indiana University, $410 \mathrm{~W} 10^{\text {th }} \mathrm{St}, \mathrm{HS} 2000$, Indianapolis, IN, 46202}

\section{Corresponding Author}

Randall W. Grout, MD, MS

Children's Health Services Research

Indiana University

410 W 10th St

HS 2000

Indianapolis, IN 46202

rgrout@iu.edu

Phone: 317-278-0552

Fax: 317-278-0456

\section{Key Words}

Adolescent, screening, quality improvement, patient reported outcomes, confidentiality

\section{Running Title}

Adolescent self-report rate on pre-visit screening

\section{Word Counts}

Abstract: 248

Main text: 3,283

\section{Funding Source}

This study was/not grant supported, although the CHICA system receives support from the Department of Health and Human Services [grant numbers R01DK092717, R01HS017939, R01HS018453, R01HS020640, R01HS022681]. No honorarium, grant, or other form of payment was given to anyone to produce or submit the manuscript.

\section{Declarations of Interest}

Dr. Downs is a co-creator of CHICA. CHICA was developed at Indiana University, a state university. In 2016, Dr. Downs co-founded Digital Health Solutions, LLC, a company created and licensed to market the CHICA software discussed in this paper. Dr. Grout has received grant 
funding from Digital Health Solutions, LLC. The remaining authors have indicated they have no potential conflicts of interest to disclose.

\section{$\underline{\text { Abstract }}$}

\section{Background}

Adolescent pre-visit screening on patient-generated health data is a common and efficient practice to guide clinical decision making. However, proxy informants (e.g., parents or caregivers) often complete these forms, which may lead to incorrect information or lack of confidentiality. Our objective was to improve the adolescent self-report rate on pre-visit screening.

\section{Methods}

We conducted an interventional study using an interrupted time-series design to compare adolescent self-report rates (percent of adolescents ages 12-18 years completing their own previsit screening) over 16 months in general pediatric ambulatory clinics. We collected data using a computerized clinical decision support system with waiting room electronic tablet screening. Pre-intervention rates were low, and we created and implemented two electronic workflow alerts, one each to the patient/caregiver and clinical staff, reminding them that the adolescent should answer the questions independently. We included the first encounter from each adolescent and evaluated changes in adolescent self-reporting between pre- and post-intervention periods using interrupted time series analysis.

\section{Results}

Patients or caregivers completed 2,670 qualifying pre-visit screenings across 19 pre-intervention, 7 intervention, and 44 post-intervention weeks. Self-reporting by younger adolescents nearly doubled with a significant increase of 19.3 percentage points (CI 9.1-29.5) from the baseline 20.5\%. Among older adolescents, the stable baseline rate of $53.6 \%$ increased by 9.2 absolute 
percentage points (CI -7.0-25.3). There were no significant pre- or post-intervention secular trends.

\section{Conclusions}

Two automated alerts directing clinic personnel and families to have adolescents self-report significantly and sustainably improved younger adolescent self-reporting on electronic patientgenerated health data instruments.

\section{What's New}

Caregivers frequently completed pre-visit screening intended for adolescents, especially among younger teens. Electronic workflow alerts sustained a nearly doubled adolescent self-report rate in younger teens, and older teen self-report rates were sustained between half and two-thirds of screenings.

\section{$\underline{\text { Abbreviations }}$}

CHICA: Child Health Improvement through Computer Automation; PSF: Pre-screener Form; PWS: Provider Worksheet; 


\section{$\underline{\text { Introduction }}$}

Patient-generated health data, including patient-reported outcomes (defined as measurement of a patient's health coming directly from the patient $)^{1}$, health risks, and behaviors can guide clinical decision making. ${ }^{2-4}$ Clinical practices may use unsupervised, self-administered screening or history questionnaires prior to a clinical visit to gather these data. After the forms are completed (often in the waiting room), they may be collected by clinic personnel for a medical provider to review, and later integrated into medical decision making and the visit documentation. While these forms are traditionally offered on paper, they are increasingly converted to electronic format and use tablets or kiosks in the waiting room, or even the patient's own computer at home, to gather responses. ${ }^{5-8}$

Pediatric care introduces complexity to this method because the patient may be unable to answer some questions posed on these forms due to developmental stage or cognitive function. In those instances, a separate informant (often the caregiver) can submit answers on behalf of the child. However, as children grow more independent in adolescent years, their own perspectives may differ from a caregiver's responses. ${ }^{9}$ This discordance is especially evident in sensitive topics such as substance abuse or sexual activity, ${ }^{10,11}$ where confidential reports from the adolescent are considered the standard of care. ${ }^{12}$ Given the prevalence and consequences of these behaviors, questionnaires appropriately targeted to adolescents should be completed independently and confidentially by capable patients. ${ }^{13,14}$ However, a 2015 national survey showed parents reported filling out $65 \%$ of these types of medical forms without the teen's involvement. ${ }^{15}$ We suspected that caregivers in our clinics were similarly completing screening forms designed for adolescents. Our objective was to improve the rate of adolescents completing their own patient-generated health data on pre-visit screening questionnaires. We hypothesized that the 
preintervention self-report rate in this setting would be low. We also hypothesized that the selfreport rate would increase following an implementation of an alert directing adolescents to complete the screening instruments on their own. We hypothesized both the secular trend and immediate level of adolescent informant self-report rate would improve after our interventions.

\section{Methods}

\section{Context}

The Child Health Improvement through Computer Automation (CHICA) system is a computerized clinical decision support system used in five urban, ambulatory pediatric clinics in the Eskenazi Health System, Indianapolis, Indiana. These safety-net county health system clinics serve a racially- and ethnically-diverse (approximately half are African-American, onequarter are Hispanic, and $10 \%$ are White) and predominantly low-income population (approximately $85 \%$ with public insurance). CHICA has been previously described in the medical and informatics literature. ${ }^{5,16}$ Briefly, after a patient registers in the clinic, CHICA receives a registration message with patient demographic data, and prepares a pre-screening form (PSF) of up to 20 yes/no patient-generated health data questions. The PSF answers are returned to CHICA to create actionable decision support recommendations for clinicians. The clinicians record their actions on the clinician-facing website integrated into the EHR for use in later encounters and visit documentation. CHICA is embedded into the routine workflow and has served over 58,000 patients in more than 415,000 encounters.

Throughout this study, we refer to patient-generated health data, but acknowledge in pediatrics these are often caregiver-reported. For patients under 12 years of age, CHICA administers PSF questions that ask for observations from caregivers, whereas patients at and over 12 years are instructed through generic on-screen header text to directly report their own answers (Figure 1). 
The questions on the PSF health risk assessment cover general topics like smoking in the home, car safety, developmental milestones, school performance, media use, and social determinants of health (e.g., food and housing insecurity). In addition, the adolescent PSF includes questions that target sensitive topics, like sexual activity, reproductive health, physical and sexual abuse or violence, depression (e.g., PHQ-2 which reflexes to PHQ-9), suicidality, or substance use (e.g., CRAFFT). The questions were worded for the lowest reading level possible while maintaining the core components of the question, and many were adapted from standardized instruments. The core text of the questions did not change based on an adolescent's age, and usually included a personalization such as the patient's name or a second-person pronoun.

CHICA leverages a custom Android tablet application called CHICLET to elicit the patientgenerated health data. ${ }^{17}$ The pre-visit screening workflow is described below and in Figure 1.

1. When a patient arrives at the clinic and is registered in the EHR for a face-to-face visit with a clinician (including well, follow-up, or sick visits), the patient's name will display on a list in the CHICLET application.

2. A receptionist staff member obtains one of many available tablets, selects the patient from the list and delivers the tablet to the patient, usually in the waiting room.

3. CHICLET asks the patient or caregiver to confirm their identity.

4. CHICLET displays a questionnaire that has a dynamic set of up to 20 questions built from a prioritized list of medical logic modules, as well as further indicated screening (e.g., M-CHAT or PHQ-9). The patient or caregiver completes the questionnaire in the waiting room (most often), vitals station, or exam room as time and clinic circumstances allow. 
5. [Added as part of study] CHICLET displays a page at the end of the questionnaire to determine who answered the questions on the tablet, asking, "What is your relationship to $<$ Patient Name $>$ ?"

\section{$\underline{\text { Intervention }}$}

We implemented two alerts to encourage adolescent patients to complete their own PSF on CHICLET. One alert reminded clinic staff that the patient should fill out the questionnaire if the patient was at least 12 years old. The second did the same for the patient's family, The first alert was displayed when the clinic staff selected the patient on the tablet (before the tablet is given to the patient, as part of step 2 above), as shown in Figure 1. This alert said, "Please tell the family that $<$ Patient Name $>$ should answer each question." Since the clinic staff had been previously instructed to do this in their routine workflow, this alert served as a reminder of existing protocol.

The second alert displayed once the patient or person completing the questionnaire clicked the "Confirm" button (after step 3 above). This patient-facing alert said, "These questions should be answered by $<$ Patient Name $>$ in private." The alert for the patient or caregiver launched on December 18, 2016, and the alert for clinic staff launched on February 1, 2017. Though both alerts were originally planned and built for a concurrent release, we initiated the patient-facing alert first to reduce clinic staff alert burden and see if it would have any effect alone. Our preliminary monitoring over a few weeks did not show a convincing effect, so we released the patient-facing alert at the next possible software upgrade. We consider the time span between the two alerts to be our intervention period.

\section{$\underline{\text { Measures }}$}


We collected data continuously between August 8, 2016 and December 10, 2017. We divided our study into three periods: pre-intervention, from August 8, 2016 to December 17, 2016; intervention, from December 18, 2016 to February 1, 2017; and post-intervention, from February 2, 2017 to December 10, 2017. On the first day of the preintervention period, we implemented a question on the prescreening tablet to determine who completed the PSF (e.g., "What is your relationship to $<$ Patient Name $>$ ?"). We included only the first encounter for each patient, and further restricted to patient encounters where: (1) the patient was between 12 and 18 years old; (2) at least 10 items were completed on the PSF (to exclude minimally-completed forms); and (3) the informant question was answered. We defined the adolescent self-report rate as the number of PSF with respondent identified as "self" divided by the total number of PSF completed per the above criteria.

\section{$\underline{\text { Analysis }}$}

Our primary data monitoring during the preintervention time period stratified the patients by age in years, and we identified an apparent break in the self-report trends of younger versus older patients. We decided a priori to evaluate our intervention with an age break at 15 years old, thus dividing our patient population into groups of 12-14-year-old ("younger adolescents") and 1518-year-old ("older adolescents") youth. We chose this age cutoff as it provided relatively balanced group samples and represented a period when adolescents are more independently recognized (e.g., established in high school, able to obtain learner's permit for driving). There was insufficient time between the two intervention components to assess their effects independently, so data between the interventions were censored from analysis. Since the interventions were applied uniformly to all clinics, we analyzed our data at the health system level. We aggregated our data by week and tested our interventions with an interrupted time 
series analysis using segmented regression. ${ }^{18}$ We chose this method because we sought generalizable knowledge from our quasi-experimental design. ${ }^{19}$ In addition, this approach provided statistical details on secular trends in the pre- and post-intervention periods. We tested for serial autocorrelation using the Breusch-Godfrey test. This project was exempt from IRB review, being classified as non-human subjects research by the Institutional Review Board at Indiana University. R statistical software (version 3.5.0) was used for all statistical analyses. ${ }^{20}$

\section{$\underline{\text { Results }}$}

There were 2,670 initial patient encounters within our study period that met/our inclusion criteria (see Figure 2). The primary exclusions happened when patients or families were not given a tablet questionnaire to complete, which typically happened because of temporary clinic workflow situations or when patients presented at a site's adolescent-focused clinic that did not use CHICA. For patients who received a tablet a completed at least one question, more than $88 \%$ continued to complete at least 10 questions and the informant question. After censoring the intervention weeks, there were 2,431 encounters in the non-intervention time periods, with an average of 14.4 encounters per week (standard deviation [SD] 8.6) among older adolescents and 24.2 encounters per week (SD 11.7) with younger adolescents. The mean patient age was 14.0 years (SD 1.8). Table 1 further characterizes our descriptive data.

Figure 3 demonstrates the adolescent self-report rate by age across the pre- and post-intervention time periods. These rates range from a low of $9 \%$ in 12 -year-olds pre-intervention, to a high of $79 \%$ in 18-year-olds at both pre- and post-intervention. The self-completion rates changed most for the younger adolescent ages, and in 17-year-olds actually decreased slightly after the intervention. When split by age group, the median self-report rate increased from $18.9 \%$ to $35.0 \%$ and $48.0 \%$ to $58.1 \%$ in younger and older adolescents, respectively. 
Figure 4 displays a run chart of adolescent self-report rates, and Table 2 shows results from the interrupted time series analysis regression. We did not find sufficient evidence of autocorrelation (such as an underlying cyclical pattern) in the time series for younger $(\mathrm{P}=0.16)$ or older $(\mathrm{P}=0.26)$ adolescents. Youth younger than 15 years had a stable $(\mathrm{p}=0.63$, indicating a slope or trend over time of zero) pre-intervention $20.5 \%$ self-completion rate, which significantly increased by 19.3 absolute percentage points (CI 9.13-29.5), or a 94\% relative increase, after the intervention. Among older adolescents, the stable $(\mathrm{p}=.40)$ baseline rate of $53.6 \%$ increased by 9.2 absolute percentage points (CI -7.0-25.3) after the intervention, which was not significant at alpha $=0.05$. There were no significant ongoing trends in the post-intervention periods for either age group or all adolescents as a whole. In the whole group analysis, there was a significant increase of 15.5 absolute percentage points (CI 7.1-23.8) from the pre-intervention baseline of $35.8 \%$. Since our pre-intervention data showed an increase in self-report rate after 16 years old (Figure 3), we conducted a sensitivity analysis by substituting an age break at 16 years old. There was no substantial change to our results using this higher age cutoff.

\section{$\underline{\text { Discussion }}$}

In this study, we established our baseline adolescent response rate for prescreening health questions within a large, urban, general pediatric ambulatory care setting. After finding the majority of the responses were not generated by the adolescent patients themselves, we also implemented two workflow alerts to remind clinic staff and families who should complete the screening form. Our intervention was associated with a significant increase in the rate of selfreporting among younger adolescents.

In our data, the adolescent self-report rate was clearly a function of age (see Figure 3). As we expected, the highest self-report rate was in the oldest adolescents who are more likely to assert 
independence or even visit the clinic alone. Our intervention had the strongest effect at younger ages; the self-report rate more than doubled for 12-year-olds. For younger adolescents, parents were, no doubt, used to filling out the forms for their children. This may have been their first experience having their teens provide their own health information. However, even after our intervention, fewer than half of adolescents below 16 years of age completed their own pre-visit surveys. Proxy responses from parents can systematically bias or diminish the utility of questions assessing sensitive behaviors for adolescents, including substance use, eating disorders, and sexual activity. ${ }^{10,21}$ A clinician's medical decision making may be affected by both false positives (informant erroneously reports an assumed risky behavior in adolescent) or false negatives (informant erroneously denies an unknown risky behavior in adolescent) resulting from parents reporting on behalf of their teens. Another negative effect of parents completing health risk assessments is that providers may begin to appropriately doubt the veracity of the answers when the "self-report" forms have answers that contradict the youth's answers in the clinical interview. We suggest that patient-reported outcomes and health risk assessments in domains where a non-patient informant could be the respondent should carry an attribute of informant identity, similar to a statement of data provenance. The clinician can assess the screening's likelihood of veracity based on the type of question (common household knowledge versus sensitive topic) and the informant's identity (adolescent versus caregiver).

We found a significant change in the rate of younger adolescent self-report rates, but it was still far from ideal. Older adolescents were naturally assuming more independence at baseline, and our intervention did not significantly increase their self-report rates. It is possible that these patients regularly attending their general pediatric appointments in their later adolescent years are a more engaged population at baseline, and we reached a natural ceiling in their self-report 
rates. This limit could be due in part to health literacy and the reading level of the questions, our clinic workflow, or even our ability to detect it with our measures. For example, the self-report rate may be partially underestimated if an adolescent starts the screening but their caregiver finishes it and answers the informant question. The clinics involved in this study were general pediatrics clinics that saw adolescents, and it is possible a more focused teen clinic would produce a higher adolescent self-report rate. In-person observation or follow-up interviews-not done in our study - could help determine the extent of these factors' contributions. In addition, we suspect some clinic personnel or families ignored the alerts, as may be expected with pop-up alert interventions. While interruptive alerts can be used effectively to guide users in healthcare software functionality ${ }^{22}$, alert fatigue is a real phenomenon that manifests after repeated alert exposure. $^{23}$

Our systematic change showed stable secular trends after the interventions. In-person skills training with role-playing or providing a specific script to clinic personnel may help achieve ongoing improvement. Most adolescents visit general pediatricians for preventive care ${ }^{24}$, yet they only account for about $20 \%$ of general pediatric office visits. ${ }^{25,26}$ When a clinic typically works with parents of children 11 years and younger, the minority panel of adolescents may inadvertently fall under the general pediatrics "culture" of focusing on parents rather than recognizing the independence of adolescents. We applaud efforts towards workflow restructuring to produce a more youth-friendly clinic that provides adolescent-centered care. ${ }^{27}$ The need for adolescent-friendly screening instruments should not be underestimated. Health literacy in this developing stage varies greatly, and the association between decreased health literacy and increased adolescent risk behaviors compounds the difficulty in identifying patientgenerated health data and addressing risks. ${ }^{28}$ We expect a small portion of adolescents to require 
caregiver assistance during pre-visit screener due to lack of capacity, but it is unlikely to be the proportions reported here. Regardless, as part of our ongoing efforts, we are reviewing the PSF screening questions to clarify any confusing concepts and better tailor to the minimum representative health literacy levels.

Adolescents indicate they want to discuss their health risks with their providers, and automated pre-visit screening can help ensure that the health system does not become the limiting factor in this care. ${ }^{29}$ Pre-visit screening of adolescent patient-generated health data brings at least three benefits to adolescent care. First, it increases disclosure of sensitive information related to health risks. ${ }^{3}$ Notably, this may not happen on the first try, but instead might help normalize the screening for health risks at future visits. Adolescents endorse the confidentiality of paper- and computer-based pre-visit screening and their increased willingness to disclose information to a form or computer than a person. ${ }^{30-32}$ Second, it primes the adolescent patient for confidential face-to-face assessments that should happen with the clinician. ${ }^{33}$ Finally, the screening results improve clinician discussion and tailor their counseling to the patient's needs. ${ }^{5,34,35}$ We reaffirm the utility of pre-visit questionnaires, and encourage further research into systematic, confidential assessments of adolescent patient-generated health data.

Adolescents intensely value a variety of privacy perspectives, ${ }^{14}$ so care providers should explore clinical workflow and physical space cues to nudge adolescents and their caregivers towards a confidential pre-visit screening. These situational features may be different for electronic workflows like ours than for a paper-based workflow. Future work should also consider the value of soliciting both adolescent and caregiver reports in parallel questionnaires. Parents both underestimate and overestimate adolescent health risks. ${ }^{36}$ These discrepancies are associated with subsequent adolescent risk involvement, ${ }^{10}$ and may indicate caregiver concerns, lack of 
caregiver knowledge, or difficulties in caregiver-adolescent communication and partnership.

The discordant topics may lead to opportunities for improved partnership between caregivers and healthcare professionals..$^{37,38}$

Our study is not without limitations. First, our study design did not have a concurrent randomized control. Using a pre-intervention control does not account for other events that may have been happening at the time of the intervention. However, the interrupted time series design is a strong quasi-experimental approach. Additionally, the CHICA team is closely involved with the clinics, and we are unable to recall any concurrent events that likely affected the adolescent self-report rate. Not all patients received a CHICLET tablet, so there may be bias in which encounters generate informant data. We assume the question assessing the informant's relationship to the patient was answered correctly, and acknowledge that some adolescents may not be capable of completing their own forms. Also, the question did not allow for multiple informants to be selected, which may occur when an adolescent and their caregiver complete the screening instruments together. Finally, our intervention used electronic tablets, and the electronic workflow may not be directly generalizable to a paper-based workflow.

\section{$\underline{\text { Conclusion }}$}

In an era of patient-generated health data, clinicians and researchers cannot simply assume the respondent's identity on clinical encounter-based, self-administered forms in clinics serving adolescent patients. Confidentiality is paramount to thorough adolescent health care, yet caregivers were completing pre-visit questionnaires in over half of adolescent encounters. Alerts directing clinic personnel to instruct the capable adolescents to fill out the form and directing the family to allow the adolescents to self-report, significantly and sustainably improved younger adolescent self-reporting on electronic patient-generated health data instruments. Older 
adolescent self-reporting did not significantly increase, but was already higher than the younger adolescent rate. End users of electronic patient-generated health data involving populations with possible proxy informants should consider and account for data provenance in downstream usage of these clinical measures. Future work should emphasize the screening environment and techniques to ensure honest and confidential adolescent patient-generated health data.

\section{$\underline{\text { Acknowledgements }}$}

We are grateful for the Child Health Informatics Research and Development Lab (CHIRDL) and their technical assistance in this work.

\section{$\underline{\text { References }}$}

1. Cella D, Hahn EA, Jensen SE, et al. Patient-Reported Outcomes in Performance Measurement. Research Triangle Park (NC): RTI Press, 2015. http://www.ncbi.nlm.nih.gov/books/NBK424378/. Accessed July 13, 2018.

2. Gadomski AM, Fothergill KE, Larson S, et al. Integrating mental health into adolescent annual visits: impact of previsit comprehensive screening on within-visit processes. $J$ Adolesc Health. 2015;56(3):267-273.doi:10.1016/j.jadohealth.2014.11.011

3. Stevens J, Kelleher KJ, Gardner W, et al. Trial of Computerized Screening for Adolescent Behavioral Concerns. Pediatrics. 2008;121(6):1099-1105. doi:10.1542/peds.2007-1878

4. Bevans KB, Moon J, Carle AC, et al. Patient Reported Outcomes as Indicators of Pediatric Health Care Quality. Acad Pediatr. 2014;14(5, Supplement):S90-S96. doi:10.1016/j.acap.2014.06.002

5. Anand V, Carroll AE, Downs SM. Automated Primary Care Screening in Pediatric Waiting Rooms. Pediatrics. 2012;129(5):e1275-e1281. doi:10.1542/peds.2011-2875

6. Fothergill K, Gadomski A, Solomon B, et al. Assessing the impact of a web-based comprehensive somatic and mental health screening tool in pediatric primary care. Acad Pediatr. 2013;13(4):340-347. doi:10.1016/j.acap.2013.04.005

7. Harris SK. Making Time for Mental Health: Computerized Previsit Screening in Primary Care. J Adolesc Health. 2015;56(3):257-258. doi:10.1016/j.jadohealth.2014.12.012

8. Harris SK, Aalsma MC, Weitzman ER, et al. Research on Clinical Preventive Services for Adolescents and Young Adults: Where Are We and Where Do We Need to Go? J Adolesc Health. 2017;60(3):249-260. doi:10.1016/j.jadohealth.2016.10.005 
9. Verhulst FC, Ende J van der. Agreement Between Parents' Reports and Adolescents' Selfreports of Problem Behavior. J Child Psychol Psychiatry. 1992;33(6):1011-1023. doi:10.1111/j.1469-7610.1992.tb00922.x

10. Yang H, Stanton B, Cottrel L, et al. Parental Awareness of Adolescent Risk Involvement: Implications of Overestimates and Underestimates. J Adolesc Health. 2006;39(3):353-361. doi:10.1016/j.jadohealth.2005.12.008

11. Young TL, Zimmerman R. Clueless: Parental Knowledge of Risk Behaviors of Middle School Students. Arch Pediatr Adolesc Med. 1998;152(11):1137-1139. doi:10.1001/archpedi.152.11.1137

12. English A, Park MJ, Shafer M-A, Kreipe RE, D’Angelo LJ. Health Care Reform and Adolescents-An Agenda for the Lifespan: A Position Paper of the Society for Adolescent Medicine. J Adolesc Health. 2009;45(3):310-315. doi:10.1016/j.jadohealth.2009.06.001

13. Ford CA, Millstein SG, Halpern-Felsher BL, Irwin CE. Influence of physician confidentiality assurances on adolescents' willingness to disclose information and seek future health care. A randomized controlled trial. JAMA. 1997;278(12):1029-1034.

14. Britto MT, Tivorsak TL, Slap GB. Adolescents' Needs for Health Care Privacy. Pediatrics. 2010;126(6):e1469-e1476. doi:10.1542/peds.2010-0389

15. Clark S, Kauffman A, Singer D, Matos-Moreno A, Davis M. Back off: Parents impeding teens' healthcare independence. CS Mott Child Hosp Natl Poll Child Health Univ Mich. 2015;25(2). http://mottpoll.org/reports-surveys/back-parents-impeding-teens-healthcareindependence.

16. Anand V, Carroll AE, Biondich PG, Dugan TM, Downs SM. Pediatric decision support using adapted Arden Syntax. Artif Intell Med. October 2015.

doi:10.1016/j.artmed.2015.09.006

17. Anand V, McKee S, Dugan TM, Downs SM. Leveraging electronic tablets for general pediatric care: a pilot study. Appl Clin Inform. 2015;6(1):1-15. doi:10.4338/ACI-2014-09RA-0071

18. Penfold RB, Zhang F. Use of interrupted time series analysis in evaluating health care quality improvements. Acad Pediatr. 2013;13(6, Supplement):S38-S44. doi:10.1016/j.acap.2013.08.002

19. Andersson Hagiwara M, Andersson Gäre B, Elg M. Interrupted Time Series Versus Statistical Process Control in Quality Improvement Projects. J Nurs Care Qual. 2016;31(1):E1. doi:10.1097/NCQ.0000000000000130

20. R Core Team. R: A Language and Environment for Statistical Computing. Vienna, Austria: R Foundation for Statistical Computing; 2018. https://www.R-project.org/. 
21. Hemmingsson H, Ólafsdóttir LB, Egilson ST. Agreements and disagreements between children and their parents in health-related assessments. Disabil Rehabil. 2017;39(11):10591072. doi:10.1080/09638288.2016.1189603

22. Turchin A, James OD, Godlewski ED, et al. Effectiveness of interruptive alerts in increasing application functionality utilization: A controlled trial. J Biomed Inform. 2011;44(3):463468. doi:10.1016/j.jbi.2010.07.002

23. Embi PJ, Leonard AC. Evaluating alert fatigue over time to EHR-based clinical trial alerts: findings from a randomized controlled study. J Am Med Inform Assoc. 2012;19(e1):e145148. doi:10.1136/amiajnl-2011-000743

24. Rand CM, Goldstein NPN. Patterns of Primary Care Physician Visits for US Adolescents in 2014: Implications for Vaccination. Acad Pediatr. 2018;18(2):S72-S78. doi:10.1016/j.acap.2018.01.002

25. Bocian AB, Wasserman RC, Slora EJ, Kessel D, Miller RS. Size and Age-Sex Distribution of Pediatric Practice: A Study From Pediatric Research in Office Settings. Arch Pediatr Adolesc Med. 1999;153(1):9-14. doi:10.1001/archpedi.153.1.9

26. American Academy of Pediatrics. Profile of Pediatric Office Visits. Elk Grove Village, IL; 2010. https://www.aap.org/en-us/Documents/practicet_Profile_Pediatric_Visits.pdf.

27. University of Michigan Health System. Adolescent Health Initiative. http://www.umhsadolescenthealth.org/. Accessed July 20, 2018.

28. Fleary SA, Joseph P, Pappagianopoulos JE. Adolescent health literacy and health behaviors: A systematic review. J Adolesc. 2018;62:116-127. doi:10.1016/j.adolescence.2017.11.010

29. Klein JD, Wilson KM. Delivering quality care: adolescents' discussion of health risks with their providers. J Adolesc Health. 2002;30(3):190-195. doi:10.1016/S1054-139X(01)003421

30. Olson AL, Gaffney CA, Hedberg VA, Gladstone GR. Use of Inexpensive Technology to Enhance Adolescent Health Screening and Counseling. Arch Pediatr Adolesc Med. 2009;163(2):172-177. doi:10.1001/archpediatrics.2008.533

31. Knight JR, Harris SK, Sherritt L, et al. Adolescents' preference for substance abuse screening in primary care practice. Subst Abuse. 2007;28(4):107-117.

32. Paperny DM, Aono JY, Lehman RM, Hammar SL, Risser J. Computer-assisted detection and intervention in adolescent high-risk health behaviors. J Pediatr. 1990;116(3):456-462.

33. Boekeloo BO, Bobbin MP, Lee WI, Worrell KD, Hamburger EK, Russek-Cohen E. Effect of Patient Priming and Primary Care Provider Prompting on Adolescent-Provider Communication About Alcohol. Arch Pediatr Adolesc Med. 2003;157(5):433-439. doi:10.1001/archpedi.157.5.433 
34. Riese A, Mello MJ, Baird J, Steele DW, Ranney ML. Prompting Discussions of Youth Violence Using Electronic Previsit Questionnaires in Primary Care: A Cluster Randomized Trial. Acad Pediatr. 2015;15(3):345-352. doi:10.1016/j.acap.2015.01.005

35. Paperny DM, Hedberg VA. Computer-assisted health counselor visits: a low-cost model for comprehensive adolescent preventive services. Arch Pediatr Adolesc Med. 1999;153(1):6367.

36. Gersh E, Richardson LP, Katzman K, et al. Adolescent Health Risk Behaviors: Parental Concern and Concordance Between Parent and Adolescent Reports. Acad Pediatr. 2018;18(1):66-72. doi:10.1016/j.acap.2017.08.012

37. Ford CA, Davenport AF, Meier A, McRee A-L. Partnerships Between Parents and Health Care Professionals to Improve Adolescent Health. J Adolesc Health. 2011;49(1):53-57. doi:10.1016/j.jadohealth.2010.10.004

38. Dittus PJ, Michael SL, Becasen JS, Gloppen KM, McCarthy K, Guilamo-Ramos V. Parental Monitoring and Its Associations With Adolescent Sexual Risk Behavior: A Meta-analysis. Pediatrics. 2015;136(6):e1587-e1599. doi:10.1542/peds.2015-0305 
Figure 1. Baseline pre-screening workflow (left) and study intervention alerts (right) on electronic tablets.
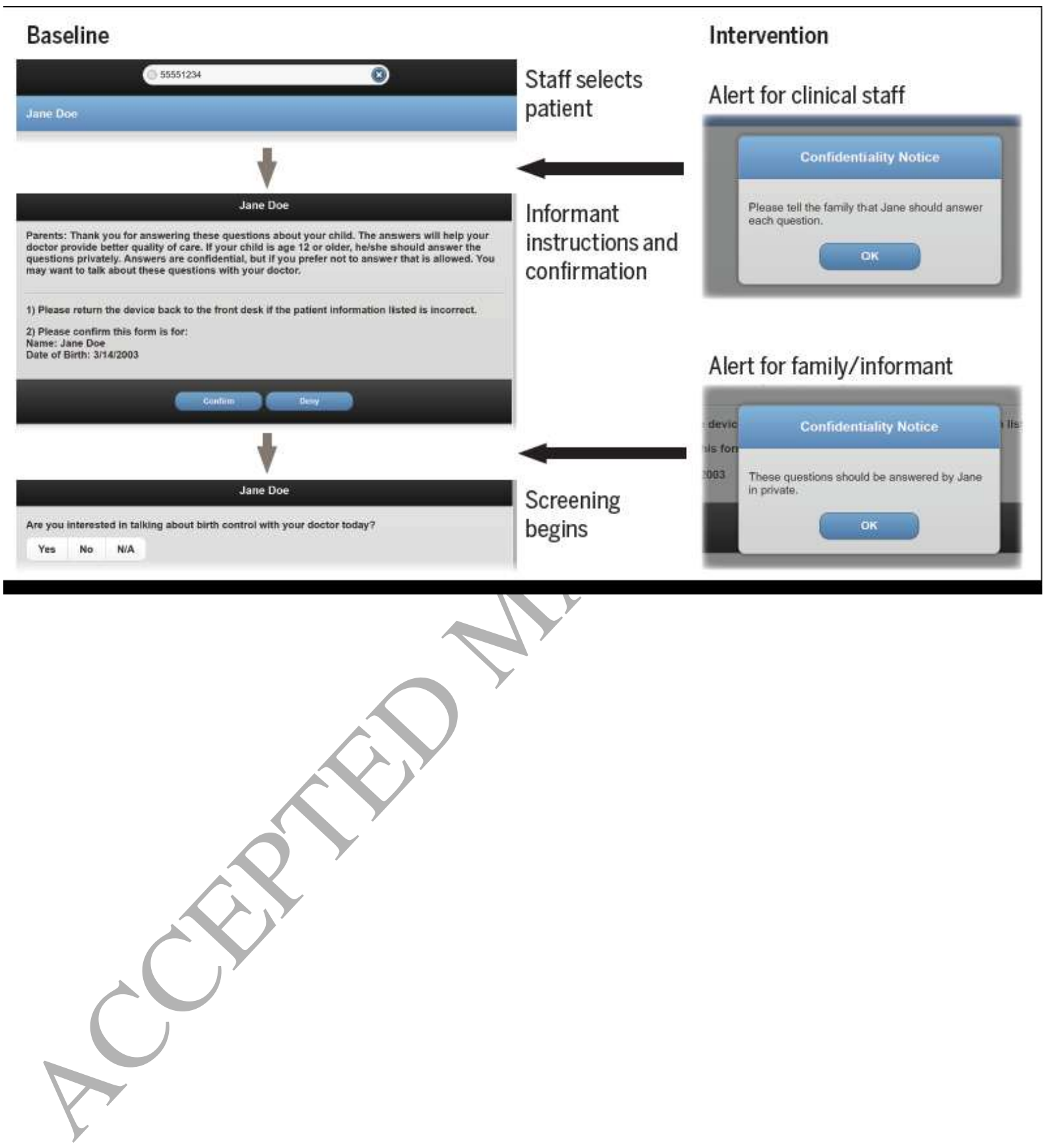
Figure 2. Study participant flow diagram. *Not mutually exclusive criteria.

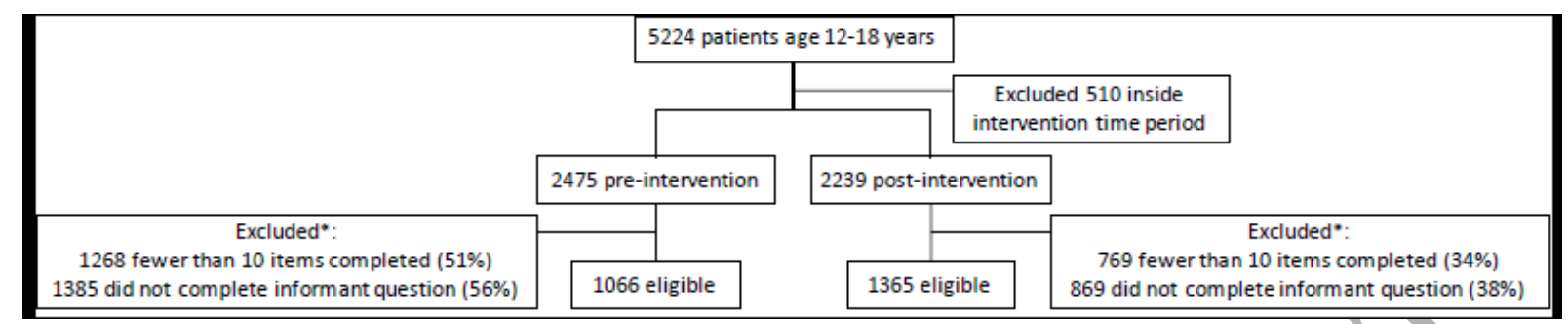

Figure 3. Change in adolescent self-report rate, averaged over pre- or post-intervention time period, by age.

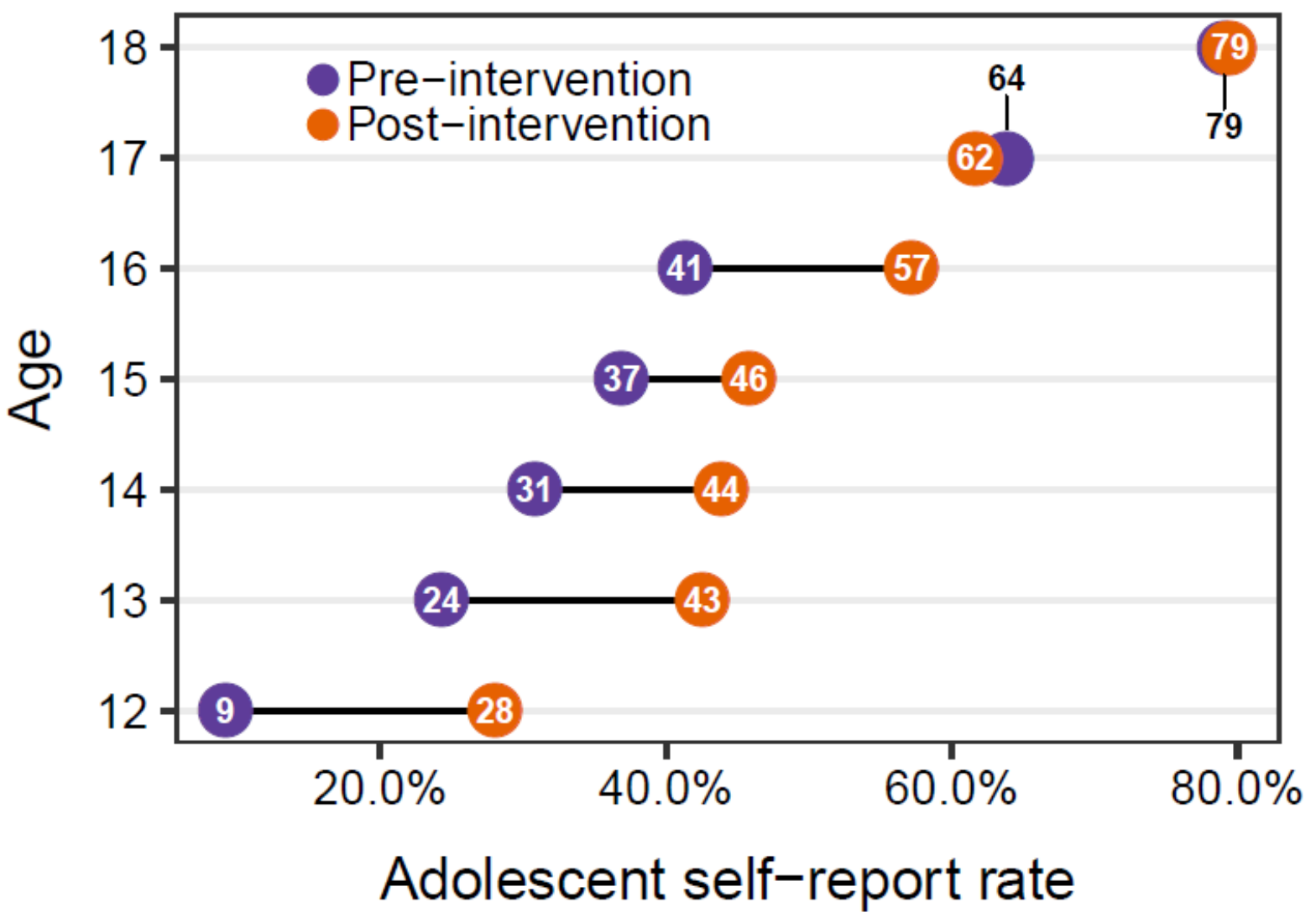


Figure 4. Run chart of adolescent self-report rate across pre-intervention, intervention, and postintervention periods.

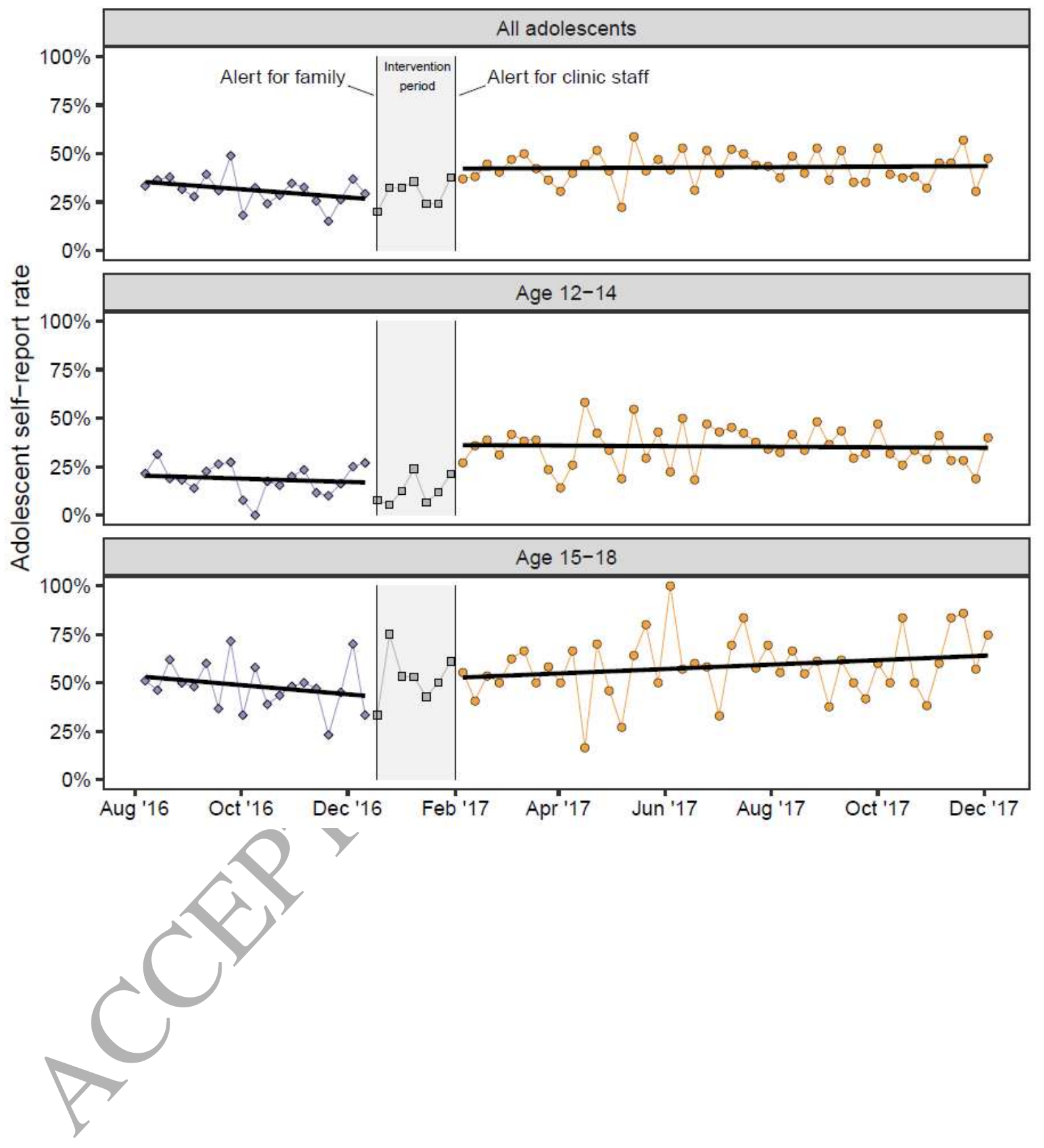


Table 1. Study demographics

\begin{tabular}{|l|l|l|l|}
\hline Characteristic & $\begin{array}{l}\text { All patient } \\
\text { encounters }\end{array}$ & $\begin{array}{l}\text { Pre- } \\
\text { intervention } \\
\text { encounters }\end{array}$ & $\begin{array}{l}\text { Post- } \\
\text { intervention } \\
\text { encounters }\end{array}$ \\
\hline $\mathrm{n}(\%)$ & 2431 & $1066(43.9)$ & $1365(56.1)$ \\
\hline Age group, n (\%) & & & \\
\hline Younger adolescents (age 12-14) & $\begin{array}{l}1527 \\
(62.8)\end{array}$ & $631(59.2)$ & $896(65.6)$ \\
\hline Older adolescents (age 15-18) & $904(37.2)$ & $435(40.8)$ & $469(34.4)$ \\
\hline Questionnaire respondent, n (\%) & & & \\
\hline Self & $926(38.1)$ & $341(32.0)$ & $585(42.9)$ \\
\hline Mother & $\begin{array}{l}1185 \\
(48.7)\end{array}$ & $558(52.3)$ & $627(45.9)$ \\
\hline Father & $152(6.3)$ & $80(7.5)$ & $72(5.3)$ \\
\hline $\begin{array}{l}\text { Other (aunt, grandparent, sibling, } \\
\text { other) }\end{array}$ & $168(6.9)$ & $87(8.2)$ & $81(5.9)$ \\
\hline Sex, $\mathrm{n}(\%)$ & & & \\
\hline Male & $\begin{array}{l}1264 \\
(52.0)\end{array}$ & $564(53.0)$ & $700(51.3)$ \\
\hline Female & $\begin{array}{l}1166 \\
(48.0)\end{array}$ & $501(47.0)$ & $665(48.7)$ \\
\hline
\end{tabular}

Table 2. Interrupted time series regression parameters for an adolescent self-report rate intervention

\begin{tabular}{|c|c|c|c|}
\hline & $\begin{array}{l}\text { All adolescents } \\
95 \% \text { confidence } \\
\text { interval) }\end{array}$ & Age 12-14 & Age 15-18 \\
\hline $\begin{array}{l}\text { Pre-intervention mean } \\
\text { adolescent self-report rate } \\
\text { (baseline) }\end{array}$ & $\begin{array}{c}35.8 * \\
(28.4 \text { to } 43.3)\end{array}$ & $\begin{array}{c}20.5 * \\
(11.5 \text { to } 29.6)\end{array}$ & $\begin{array}{c}53.6 * \\
(39.3 \text { to } 68.0)\end{array}$ \\
\hline $\begin{array}{l}\text { Pre-intervention trend (change } \\
\text { in adolescent self-report rate } \\
\text { per week) }\end{array}$ & $\begin{array}{c}-0.5 \\
(-1.1 \text { to } 0.2)\end{array}$ & $\begin{array}{c}-0.2 \\
(-1.0 \text { to } 0.6)\end{array}$ & $\begin{array}{c}-0.5 \\
(-1.8 \text { to } 0.7)\end{array}$ \\
\hline $\begin{array}{l}\text { Post-intervention change in } \\
\text { mean adolescent self-report } \\
\text { rate (intervention) }\end{array}$ & $\begin{array}{c}15.5 * \\
\text { (7.1 to } 23.8)\end{array}$ & $\begin{array}{c}19.3 * \\
(9.1 \text { to } 29.5)\end{array}$ & $\begin{array}{c}9.2 \\
(-7.0 \text { to } 25.3)\end{array}$ \\
\hline $\begin{array}{l}\text { Post-intervention trend } \\
\text { (change in adolescent self- } \\
\text { report rate per week) }\end{array}$ & $\begin{array}{c}0.5 \\
(-0.2 \text { to } 1.2)\end{array}$ & $\begin{array}{c}0.2 \\
(-0.7 \text { to } 1.0)\end{array}$ & $\begin{array}{c}0.8 \\
(-0.5 \text { to } 2.1)\end{array}$ \\
\hline
\end{tabular}

